\title{
Revision of the Biological Monitoring Working Party (BMWP) Score System: Derivation of Present-only and Abundance-related Scores from Field Data
}

\author{
MF Paisley, DJ Trigg \& WJ Walley \\ Centre for Intelligent Environment Systems \\ Staffordshire University \\ ST18 0AD \\ United Kingdom
}

\begin{abstract}
The Biological Monitoring Working Party (BMWP) score system was introduced in 1980 to provide an index of river water quality for England and Wales based on aquatic macro-invertebrates. The score allocated to each taxon was set by a group of expert river biologists based upon their collective experience of the taxon's sensitivity to organic pollution (Hawkes, 1997). This paper describes an objective reappraisal of these subjectively-derived scores through the statistical analysis of a large and comprehensive database of field samples. Using the analytical approach of Walley \& Hawkes (1996, 1997) two different methods of using biological and environmental data were evaluated as a basis for revising BMWP scores, both of which accounted for variations in site type. One method, MNWH (Modified New Walley Hawkes), used MASPT (a Modified Average Score Per Taxon) as its ranking metric and required analyses performed on separated data sets divided into three sites types. The other method already accounted for type effects and was based on EQI (Environmental Quality Index) based on MASPT to provide its ranking metric. Both of these methods involved the use of modified BMWP scores for Oligochaeta and Chironomidae for reasons that are explained and justified. Following evaluation the investigation proceeded using the MNWH methodology to derive present-only (PO) and abundance-related (AR) scores for the BMWP taxa (and 19 additional taxa mostly from the order Diptera plus 16 extra taxa resulting from the splitting of eight BMWP composite taxa). The MNWH scores are shown to be generally in keeping with Walley \& Hawkes (WH) scores, except for a few rare taxa that were represented by very small samples in the Walley \& Hawkes study.
\end{abstract}

Key words: river, quality, pollution, classification, monitoring, biology, biotope, benthic, macroinvertebrates, biotic indices, BMWP, Water Framework Directive

\section{INTRODUCTION}

\subsection{Background}

The Biological Monitoring Working Party (BMWP) score system (BMWP, 1978; Chesters, 1980; Hawkes, 1997) has been used by the regulatory authorities in the United Kingdom as the basis of their river invertebrate status classification system since 1980. Because of its advantages modifications of the BMWP score system have been developed for use in a number of other countries including Spain (Zamora-Munoz and Alba-Tercedor, 1996), Argentina (Capítulo et al., 2001), Poland (Kownacki et al., 2004) and Thailand (Mustow, 2002).

In the UK BMWP scores are used in conjunction with RIVPACS (River Invertebrate Prediction and Classification System; Moss et al., 1987; Wright et al., 1993; Wright et al., 2000) as a means of classifying river water quality. The biological General Quality Assessment (GQA) of river status is based on ecological quality indices (EQIs, also known as 'observed/expected' (O/E) ratios) consisting of observed values of biotic indices as a proportion of their expected values under non-impacted conditions, as predicted by RIVPACS. The GQA is based on EQIs for two indices: ASPT (average BMWP score per taxon) and NTAXA (the number of BMWP taxa found in the sample). These EQls are split into bands 
that define the quality classes: 'a' (very good) to 'f' (bad) (Hemsley-Flint, 2000). Similar systems have been developed for use in Australia (Smith et al., 1999; Davies, 2000), some states of US (e.g. Hawkins et al., 2000; Hawkins, 2006; Hargett et al., 2007), and the Czech Republic (Kokes et al, 2006) for example.

The key principles underlying the RIVPACS approach, such as reference sites and O/E ratios, were subsequently incorporated into the biological assessment systems specified by the Water Framework Directive (WFD; European Commission, 2000), which sets ecological standards for surface water across the 27 countries of the European Union. Biological quality metrics being adopted under the Directive are based on taxonomic composition, richness and abundance of a range of 'biological quality elements': in freshwaters these are phytoplankton, macroinvertebrates, macrophytes \& phytobenthos (diatoms) and fish. Under the WFD, the range of O/E ratios is divided into five classes: high, good, moderate, poor and bad. The 'expected' values relate to a consistent 'reference' state defined by low level of environmental pressure and the resulting observed/reference values are known as Ecological Quality Ratios (EQRs).

The stipulated target of the WFD is that all water bodies in the EU achieve good ecological status by 2015. To help facilitate this in the United Kingdom RIVPACS itself has recently been updated to predict index values at reference state and to calculate EQRs for the WFD. The revised version (RIVPACS IV) is implemented in software known as RICT (River Invertebrate Classification Tool; Davy-Bowker et al., 2008). RIVPACS IV has an updated database of reference sites and a simplified algorithm for predicting biotic indices. RICT will be able to calculate an extended range of biotic indices relating to specific stresses as well as ecological and functional traits. The range of indices was reviewed recently by Clarke et al., 2011 and includes biotic indices for organic pollution and general degradation such as ASPT and NTAXA when based on the original BMWP scores, and when based on the revised scores that are the subject of this paper.

Other biotic indices include those for acidification (AWIC; Acid Water Indicator Community) for families (Davy-Bowker et al., 2005) and species (Murphy et al., 2011), flow stress (LIFE; Lotic-Invertebrate Index for Flow Evaluation, Extence et al., 1999), sedimentation stress (PSI; Proportion of Sediment-Sensitive Invertebrates, Extence et al., 2011), hydromorphology (GSFI; German Stream Fauna Indices, Lorenz et al., 2004), pesticides (SPEAR; Species at Risk, Beketov et al., 2008) and community richness and rarity (CCl; Community Conservation Index, Chadd and Extance, 2004).

The original BMWP scores were derived by expert opinion and reflect the perceived sensitivity of river invertebrate families to organic pollution (Hawkes, 1997). However a more objective approach to allocating BMWP scores was developed by Walley and Hawkes $(1996,1997)$ including the use of abundance data. This is hereafter referred to as the ' $\mathrm{WH}$ ' method. It was anticipated that the incorporation of improved scores into RICT would provide a more accurate and precise representation of environmental impacts on the invertebrate fauna and, consequently, better informed direction of resources for the remediation of problems. Although the revised scores derived by WH have been used elsewhere (for example see Hassall et al., 2010) they were never formally adopted by the regulatory authorities. However many biologists within the Environment Agency of England and Wales (EA) felt that they better reflected the differential sensitivities of the taxa to the combined effects of organic pollution and other major pressures than the original scores. This paper summarises a recent study commissioned by SNIFFER (Scottish and Northern Ireland Forum for Environmental Research) in conjunction with the EA to revise the BMWP scores, based on the approach of Walley and Hawkes $(1996,1997)$, with specific reference to the derivation of the new present-only (PO) and abundancerelated (AR) scores for each of the BMWP taxa. These scores have since been adopted for use across the UK with minor amendments such as the smoothing of some AR scores.

\subsection{Lower-bound basis of BMWP}

The Biological Monitoring Working Party allocated their scores to families (and to class Oligochaeta) on the basis of their collective subjective opinion of the pollution sensitivities of the species belonging to each taxon. However, the scores allocated were based on the most pollution-tolerant species within each family (Hawkes, 1997). Thus they were not representative of the family as a whole, but of the lowerbound or worst possible case. For most families, the negative deviation of this lower-bound score below the truly representative score would have been relatively small, but not so in the case of Oligochaeta and Chironomidae. These two taxa contain many species, a few of which are highly tolerant of organic pollution, but many others of which are not. The score for Oligochaeta (one) was based on Tubifex 
tubifex and that for Chironomidae (two) was based on Chironomus riparius, both of which are highly tolerant species. Thus, the allocated scores for these two taxa were far from representative of the taxon as a whole and reflect the weakness in the subjective approach adopted.

\subsection{Towards a more representative approach}

Although this lower-bound approach is not ideal as a basis for deriving unbiased predictions of river quality, the BMWP score system presently provides the best available means of ranking sites in terms of their river quality. Random errors due to the subjective derivation of the individual scores are much reduced by the fact that ASPTs (Average Score Per Taxon) are usually averaged over 10-30 taxa. Thus the errors tend to be self-cancelling. Errors caused by the exceptionally low scores of Oligochaeta and Chironomidae do not normally upset the ranking of sites because these two taxa are present in the vast majority of samples. However, site type does have the potential to distort the rank order of the sites in terms of quality, because it affects the composition of the biotic community. Fast flowing riffle sites, for example, tend to contain more high scoring taxa than slow flowing pool sites, even where the sites are qualitatively the same in terms of river water quality. Thus, the ranking of sites in terms of their ASPTs can only be made truly representative of their river qualities if the confounding effect of site type is taken into account. If this is done, field data can be used to reappraise the scores of each taxon, simply from the distribution of its occurrence within the quality ranking list. The scores thus derived are less subjective and representative (not lower-bound) scores, and therefore better suited for the prediction of unbiased river water quality classifications. It is perhaps worth noting here that the Working Subgroup of BMWP (chaired by WH Hawkes) recommended that separate scores be allocated for eroding and depositing substrata, but this proposal was not adopted by the full Working Party (Hawkes, 1997).

\subsection{Objectives}

The main objectives of the study described in this paper were firstly to derive a revised set of PO scores for the BMWP taxa, and secondly to extend the system by deriving a corresponding set of AR scores. These modifications, when implemented, will enable the British river quality classification system to conform to the Water Framework Directive's requirement that the abundance of invertebrates be taken into account when assessing river quality status. Although separate scores for each of the site types were not required by the sponsors of the study, they were of necessity derived as part of the analysis and will be reported in a separate paper.

\section{METHODOLOGY}

\subsection{Background}

The analytical method developed by Walley and Hawkes (1996) assumed the following.

- The original BMWP scores provide the 'best available' estimate of each taxon's 'true' sensitivity to pollutional stress.

- The value of ASPT for a given site, being an average of such scores, provides the 'best available' estimate of the state of the site with respect to pollutional stress, provided the confounding effects of site type are effectively removed.

- The overall mean ASPT of the sites at which a family occurs provides a reliable statistic on which to rank the actual sensitivities of families, provided the confounding effects of site type are effectively removed.

Walley \& Hawkes accounted for site type effect by splitting the data into three site types and analysing each separately. The ASPT ranking was then used to derive revised BMWP scores based on a mapping equation which was calibrated using a set of commonly occurring taxa (known as the 'primary list') for each site type. The mapping was defined so that the mean and standard deviation of the BMWP scores was preserved for the families in the primary list, and hence approximately preserved for all the BMWP families. The reason for not using the whole set of BMWP taxa to perform the mapping is that the inclusion of rare taxa might introduce outliers that would distort the mapping. Note that this does not negate the value of rare species but merely allows the mapping to proceed on a sound basis for all species. 
Having defined the memberships of the primary lists, a mathematical mapping from the mean ASPT values (for all samples in which each family occurred) to the revised BMWP scores can be determined. It is perhaps worth noting here that Walley et al. (2001) used this methodology, in suitably modified form, to reappraise the saprobic values and indicator weights used in Slovenia.

\subsection{Choice of metric}

An alternative to the method of Walley \& Hawkes $(1996,1997)$, which split the data into discrete site types, was to use $\mathrm{EQI}_{\mathrm{ASPT}}$ as the ranking metric, defined as the ratio of the observed ASPT of the sample to the predicted ASPT in unstressed conditions as derived by RIVPACS (Moss et al. 1987). Since this metric already accounts for site type in a continuous manner, this approach avoids the need to split the data into discrete types. Hence the following metrics were tested initially:

ASPT split into 3 discrete site types as per WH but referred to here as New WH (NWH) for this new analysis;

$$
E I_{\text {ASPT }} \text { (referred to as } E Q I_{A S P T} \text { ). }
$$

Two further metrics were developed to counter the effects of the unrepresentative scores for Oligochaeta and Chironomidae. Both Oligochaeta and Chironomidae are likely to be present in polluted waters, and samples from very poor quality rivers normally contain very few taxa (typically less than five) but almost always include these two. Their exceptionally low BMWP scores are likely to result in excessively low ASPT values for such samples, which in turn are likely to translate into low revised scores when the Walley \& Hawkes algorithm is applied. The proposed solution was to allocate more representative BMWP scores to Oligochaeta and Chironomidae, then recalculate the ASPT's of all sites in the project database and repeat the NWH and $\mathrm{EQI}_{\mathrm{ASPT}}$ analyses.

In addition it was anticipated that, based on work by Clarke \& Davy-Bowker (2006), the reliability of RIVPACS predictions of the 'unstressed' state varied according to geographical location and other site characteristics. In particular, it was anticipated that predicted ASPTs for lowland sites were likely to underestimate their 'unstressed' values, resulting in the overestimation of the site's EQI. Hence when the $\mathrm{EQI}_{\mathrm{ASPT}}$ values in the project database were recalculated a new 'quality adjustment' algorithm was used, developed in an attempt to correct the effects of poorer quality reference sites on RIVPACS predictions. This exercise was carried out by EA staff and incorporated the modified BMWP scores for Oligochaeta and Chironomidae. The scores allocated were 3.5 and 3.6 respectively, obtained by averaging the presence only scores obtained by the NWH and EQI MASPT metrics above (and remarkably close to the scores of 3.5 and 3.7 respectively produced by $\mathrm{WH}$ ).

Since the new analyses were based upon modified values of ASPT (MASPT ie modified ASPT), they are

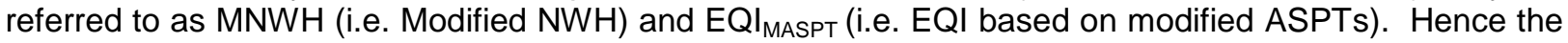
two further metrics were:

$$
\begin{aligned}
& \text { MASPT split into } 3 \text { discrete site types referred to as Modified NWH (MNWH); } \\
& \text { EQI } \\
& \text { MASPT (referred to as EQI } \\
& \text { MASPT). }
\end{aligned}
$$

\subsection{The data}

The data used in this study covered the whole of the United Kingdom for the period $1995-2004$. They were supplied by the Environment Agency for England and Wales (EA), the Scottish Environment Protection Agency (SEPA) and the Northern Ireland Environment Agency (NIEA). Thus, the project database was far bigger and more extensive than that used by $\mathrm{WH}$, which used data from England and Wales recorded in 1995. Sampling was carried out according to standardised procedures for collection and analysis (Murray-Bligh et al., 1997), and each sample consisted of the abundances of around 160 taxa, including those of the BMWP, on a logarithmic scale (abundance level 1: 1-9 specimens; 2: 10-99; 3:100-999 and 4: 1000+). However, not all of the sample records in the database contained all of the data necessary for each of the analyses. The number of valid samples available for the metrics based on NWH (or MNWH) and $\mathrm{EQI}_{\mathrm{ASPT}}$ (or $\mathrm{EQI}_{\mathrm{MASPT}}$ ) were 87809 and 50828 respectively, which are considerably greater than that the 17353 in the WH study. 
The NWH and MNWH approaches, like that of WH (Walley \& Hawkes; 1996, 1997), relied on splitting the samples into three discrete site types (riffle, riffle/pool and pool) according to the percentage composition of the substrate. A site was deemed a riffle if the proportion of boulders and pebbles was $\geq 70 \%$, a pool if the proportion of sand and silt was $\geq 70 \%$, otherwise it was a riffle/pool (that is, neither riffle nor pool). The breakdown of site type in the dataset was $63 \%$ riffles, $18 \%$ pools and $19 \%$ riffle/pools.

\subsection{Modifications to the taxonomy}

Prior to the recalculation of scores some changes were made to the BMWP taxonomic list. These consisted of modifications to some of the existing composite taxa, the removal of families for which there was a lack of sample data and the introduction of additional families for which there were data.

The majority of modifications to the composite taxa involved splitting them up into their constituent families. The composite taxa involved were: Planariidae (including Dugesiidae), Ancylidae (including Acroloxidae), Hydrobiidae (including Bithyniidae), Gammaridae (including Crangonyctidae \& Niphargidae), Hydrophilidae (including Hydraenidae), Dytiscidae (including Noteridae) and Rhyacophilidae (including Glossosomatidae). The only exception was Psychomyiidae (including Ecnomidae), which was split but Ecnomidae was subsequently removed owing to a lack of sample data. The remaining BMWP composites taxa: Siphlonuridae (including Ameletidae), Limnephilidae (including Apatanidae) and Tipulidae (including Cylindrotomidae, Limoniidae \& Pedicidae) were all retained as composites.

The BMWP families removed due to a lack of data were Lestidae, Corduliidae and Gomphidae.

The families introduced were predominantly in the order Diptera: namely, Athericidae, Ceratopogonidae, Chaoboridae, Culicidae, Dixidae, Dolichopodidae, Empididae, Ephydridae, Muscidae, Psychodidae, Ptychopteridae, Rhagionidae, Sciomyzidae, Stratiomyidae, Syrphidae and Tabanidae. Three other families in different orders were also introduced: namely, Dreissenidae (Mollusca), Veliidae (Hemiptera) and Sisyridae (Neuroptera).

\subsection{Definition of the primary lists}

Primary lists were derived for each site type and metric using the WH procedure described earlier, but using the modified taxonomic list and an increased threshold of 15 (from 5 used by WH).

\subsection{Mathematical Formulation}

The following steps describe the method by which revised present-only (PO) scores were calculated for each metric. They are written in terms of the NWH metric but apply to the others with appropriate change of notation. The steps include the split into discrete site types required for the NWH and MNWH metrics, but which is not required for $\mathrm{EQI}_{\mathrm{ASPT}}$ and $\mathrm{EQ} \mathrm{I}_{\mathrm{MASPT}}$.

(a) Calculate the mean ASPT, $A_{i j}$, for all samples from type $i$ sites in which family $j$ occurs:

$$
A_{i j}=\frac{1}{N_{i j}} \sum_{n=1}^{N_{i j}} a_{i j n}
$$

where:

$i=1$ for riffles, 2 for mixed riffle/pools and 3 for pools;

$a_{i j n}=$ ASPT of $\mathrm{n}^{\text {th }}$ sample from sites of type $i$ where family $j$ occurred.

$N_{i j}=$ number of samples from sites of type $i$ at which family $j$ occurred. 
(b) Calculate the mean, $\bar{A}_{i}$, and standard deviation, $S_{i}$, of derived $A_{i j}$ values over all families in the type $i$ primary list:

$$
\bar{A}_{i}=\frac{1}{M_{i}} \sum_{m=1}^{M_{i}} A_{i m} \quad S_{i}=\sqrt{\frac{1}{M_{i}-1} \sum_{m=1}^{M_{i}}\left(A_{i m}-\bar{A}_{i}\right)^{2}}
$$

where $M_{i}$ is the number of families in the type i primary list.

(c) Use the mean and standard deviation from (b) to calculate normalised values for all $A_{i j}$ values:

$$
z_{i j}=\frac{A_{i j}-\bar{A}_{i}}{S_{i}}
$$

(d) Estimate the revised score for family $j$ in type $i$ sites as:

where:

$$
\beta_{i j}=\bar{B}_{i}+\bar{z}_{i j} S_{B i}
$$

$\bar{B}_{i}=$ mean BMWP score of families making up the type $i$ primary list,

$S_{B i}=$ standard deviation of the BMWP scores making up the type $i$ primary list.

This step in effect equates the normalised revised BMWP scale with the normalised scale of the mean ASPTs for each family.

(e) Derive the overall score for the family $j$ :

$$
\beta_{j}=\sum_{i=1}^{3} w_{i j} \beta_{i j}
$$

where $w_{i j}=$ the proportion of samples containing family $j$ which came from type $i$ sites.

In Walley and Hawkes $(1996,1997)$ the analysis was undertaken by further splitting the data for each site type by region of origin and in effect averaging the scores derived for each region. It is recognised however that the regional division of the United Kingdom by the Agencies is arbitrary and that the regions created may change with time (as they have since the WH study). In view of this the data was aggregated over the regions and the UK treated as a whole.

Note finally that to generate abundance-related (AR) scores steps (a)-(e) were undertaken with the data split according into the abundance ratings described earlier.

\section{RESULTS}

\subsection{Results of tests on the original $N W H$ and $E Q I_{A S P T}$ metrics}

Space constraints do not permit the listing of all scores for each taxon derived by both metrics. However the NWH and $\mathrm{EQI}_{\mathrm{ASPT}}$ metrics gave revised a set of scores each that, although different, were credible in both cases, except for the abundance-related scores of a few highly tolerant taxa at high abundance levels. For example, the scores derived by the EQI $\left.\right|_{A S P T}$ metric for Lymnaeidae, Physidae, Oligochaeta, Glossiphonidae, Erpobdellidae, Asellidae, and Chironomidae when occurring in high abundance levels ranged from -2.8 to -11.1 . The corresponding range for the NWH metric was +1.4 to -4.0 . Very low values such as these were anticipated as a consequence of the unrepresentative scores for Oligochaeta and Chironomidae, and were the motivation for repeating the analyses with the new metrics based on modified scores for these taxa. 


\subsection{Results of tests on the modified MNWH and EQI $I_{M A S P T}$ metrics}

The MNWH and EQI $I_{M A S P T}$ metrics also produced sets of scores that, although different, were credible in both cases, except for a few AR scores of pollution tolerant taxa. However the range of exceptionally low abundance-related scores at high abundance levels for the seven taxa listed above was reduced to -1.4 to -8.1 in the case of the EQI ${ }_{\text {MASPT }}$ metric, and to +2.2 to -1.6 in the case of the MNWH metric. In fact the MNWH metric produced negative scores for only two of the taxa: Asellidae (-1.6 at abundance level 4) and Erpobdellidae (-0.8 at abundance level 3).

\subsection{Final scores based on MNWH metric}

The method finally adopted was the MNWH approach for reasons that are discussed below. The PO and AR scores appear in Table 1 along with the number of samples used to derive each score. For comparison the table also includes 'Pre-BMWP' scores (see below), the original BMWP scores and the WH scores.

\section{DISCUSSION OF RESULTS}

\subsection{Comparison of scores based on MNWH and EQIMASPT metrics}

The modification made to the BMWP scores of Oligochaeta and Chironomidae clearly had the required effect of reducing the magnitude of the negative AR scores. However, the EQI MASPT $_{\text {model still produced }}$ scores that intuitively seemed to be excessively low to EA's experienced limnologists. In this respect the MNWH model could be considered the more credible of the two models. However it appeared to be only marginally better overall since only $52 \%$ of its revised PO scores of the taxa were closer to their original BMWP scores than those produced by EQI MASPT $_{\text {. }}$

When tested against a set of scores produced by Working Subgroup of BMWP, prior to modification by the full committee (Hawkes, 2007), 61.4\% of the MNWH revised scores were closer to these 'Pre-BMWP' scores than those produced by EQI MASPT. The significance of this result is that the members of the Working Subgroup were all experienced field limnologist, whereas many members of the full BMWP committee were not. Thus this set of data could be considered to be the best available expert opinion of the 'true' scores. While not wishing to return to a subjective basis for judgement, the fact that MNWH performed rather better than $\mathrm{EQI}_{\text {MASPT }}$ in relation to these scores was a significant point in its favour. A correlation analysis summarised in Table 2 shows further that the MNWH metric performed better than the $E Q I_{\text {MASPT }}$ metric in terms of slope, regression coefficient $(R)$ and standard error of estimate on both the BMWP and Pre-BMWP datasets, but especially so on the Pre-BMWP set.

Full details of the results of the above tests can be found in Paisley et al (2007), together with the sets of scores based on all metrics. However in view of space constraints and the apparent advantages of the revised scores produced by the MNWH metric only these scores are discussed further.

\subsection{The complete set of scores based on MNWH metric}

Table 1 summarises the PO and AR scores derived using the MNWH metric. Where composite taxa have been split each of the component taxa has been allocated its composite BMWP score. The corresponding scores for the removed BMWP composite taxa are given in Table 3 and are provided to allow the evaluation of scores based on historical data in which the individual families may not have been recorded. New scores are given in Table 1 for all taxa concerned, except Ecnomidae for which there was insufficient data.

The scores derived using the MNWH metric are the mean of the three site-related scores weighted according to sample sizes. The total number of samples upon which each score has been based is given and this provides a guide to the score's relative reliability. There has been a considerable increase in the amount of data available over that used in the WH study. However, it is likely that the reliability of 
a few of the new scores is still questionable, for example those of Hirudinidae, Siphlonuridae, Potamanthidae, Lestidae, Gomphidae and Mesoveliidae, owing to their small sample sizes.

\subsection{Comparisons between MNWH present-only scores, the BMWP and WH scores}

The following comparisons are restricted to PO scores since the BMWP scores were PO scores. Figure 1 shows the distribution of BMWP and MNWH scores in terms of the number of taxa having scores within each unit wide (i.e. \pm 0.5 ) score band. The exceedingly uneven distribution of the original BMWP scores (Figure 1(a)) is immediately apparent, whereas the distribution of MNWH scores (Figure 1(b)) is clearly smoother and more bell-shaped curve suggesting that the MNWP scores may be better than the BMWP scores in this regard.

Average scores derived from BMWP, MNWH and WH for each of the main taxonomic groups are given in Table 4. The groups have been ordered according to the magnitude of the difference between the BMWP and MNWH scores. It is clear from this table that the average scores from the main taxonomic groups derived by MNWH are very similar to those derived by $\mathrm{WH}$, except for one notable exception, Oligochaeta. This, however, is an exceptional case which will be discussed later together with Chironomidae. When compared to the BMWP scores it is clear that some taxonomic groups have noticeably increased or decreased their scores whilst others have remained much the same. A good example of the latter is the Mollusca group. It's BMWP and MNWH average scores were 4.2 and 4.3 respectively and four of its constituent taxa had BMWP scores of 6 and the remaining six had scores of 3. Inspection of the MNWH scores for these taxa (Table 1) shows that they closely reflected the two different scores allocated by the BMWP. However the average MNWH scores for the Plecoptera group was 1.2 above that of its BMWP average score, which is exactly in keeping with the findings of Walley and Hawkes (1996), and indicates that their sensitivity to pollution was underestimated by the BMWP. The most sensitive of all was Perlidae with a score of $12.7(\mathrm{BMWP}=10, \mathrm{WH}=12.5)$, and least sensitive was Nemouridae with a score of $9.3(\mathrm{BMWP}=7, \mathrm{WH}=9.1)$. At the other end of the scale, the average MNWH score of 6.2 for the Anisoptera (Dragonflies) group is noticeably less than its BMWP score of 8.0 $(\mathrm{WH}=6.6)$, indicating that the BMWP overestimated the sensitivity of this group.

It is particularly interesting to note that the average MNWH scores for the caseless and cased Trichoptera groups were identical at 8.0, which contrasts with their average BMWP scores of 7.0 and 9.4. Although it appears that the perceived difference between these two groups is nonexistent, there are noticeable differences in scores within each group. The most sensitive taxon in the caseless group was found to be Philopotamidae with a MNWH score of $11.2(\mathrm{BMWP}=8, \mathrm{WH}=10.6)$, and the most insensitive was Psychomyiidae with a MNWH score of $5.8(B M W P=8, W H$ 6.9). Although Philopotamidae had a relatively low sample size (333) in the WH study it was much greater in this study (2106), so the new score is likely to be more reliable. The most sensitive taxon in the cased Trichoptera was Odontoceridae with a MNWH score of $11.0(B M W P=10, W H=10.9)$ and the least sensitive was Hydroptilidae with a MNWH score of $6.2(\mathrm{BMWP}=6, \mathrm{WH}=6.7)$.

It is also interesting to note those taxa with MNWH scores that are significantly different from their BMWP scores. Seven had scores that were more than 2.0 above their BMWP score: Oligochaeta $(+3.5)$, Gyrinidae (+3.2), Philopotamidae (+3.2), Perlidae $(+2.7)$, Chironomidae $(+2.6)$, Hydrophilidae $(+2.4)$, Nemouridae $(+2.3)$, but only Hydrophilidae (a BMWP composite taxon) differed unexpectedly $(+2.4)$ from its WH score. However, the MNWH scores of its two components Hydrophilidae and Hydraenidae were significantly different, being 6.2 and 8.9 respectively, thus its composite score (7.4) would be fairly sensitive to the relative proportions of each from one dataset to another. Nine taxa had MNWH scores that were more than 2.0 below their BMWP scores: Phryganeidae (-4.5), Libellulidae (-3.9), Hirudinidae (3.8), Molannidae (-3.4) Aeshnidae (-3.3), Leptoceridae (-3.3), Coenagriidae (-2.5), Psychomyiidae (-2.1) and Nepidae (-2.1). Most of them were also about 1.0 below there WH scores. However, five of them were relatively rare taxa so this was probably due to the evaluation of their scores benefitting from the five-fold increase in the size of the dataset used in this project. The remaining three taxa (Leptoceridae, Coenagriidae and Psychomyiidae) are fairly common, and clearly more tolerant of pollution than originally thought by the BMWP. 


\subsection{The MNWH abundance-related scores.}

Tables 1 and 3 list all of the MNWH abundance-related scores derived in this study. No comparisons can be made here with BMWP scores since they were PO scores. However comparisons can be made with the WH scores using unpublished data from the original study, given in Table 1. Figure 2 shows how the MNWH and WH AR score varies with abundance level for a selection of commonly occurring pollution sensitive and pollution tolerant taxa. Since the WH scores were based on smaller sample sizes than the MNWH scores, it was not always possible to derive scores for abundance level 4 , and the scores for the other abundance levels cannot be considered as reliable as the MNWH scores. Nevertheless, there is a remarkable close similarity between them (except for Oligochaeta and Chironomidae), which is reassuring. A noticeable feature of these graphs is that the scores of pollution sensitive taxa tend to increase with abundance level and vice versa for the pollution tolerant taxa, as one would be expect. These same characteristics were reported and discussed by Walley and Hawkes (1997), albeit separately for riffle and pool site types.

\subsection{Extension of taxonomy.}

Table 1 gives PO and AR scores that were derived for sixteen new taxa in the order Diptera. Their derived PO scores ranged from 1.9 to 9.6 and they were fairly uniformly distributed across that range. Scores were also derived for Dreissenidae (Mollusca), Veliidae (Hemiptera) and Sisyridae (Neuroptera, Planipennia). It is anticipated that together these could provide a valuable addition to the monitoring system.

\subsection{Special case of Oligochaeta and Chironomidae}

The BMWP taxa Oligochaeta and Chironomidae were never really suitable for use as biological indicators of river quality because each contains a vast number of species that span a very wide range of pollution sensitivity / tolerance. Thus they both lack the necessary specificity that is required of a worthwhile representative indicator. Unfortunately, the BMWP did not allocate representative scores to the taxa, but 'lower-bound' scores as described earlier. For a system that was intended to provide statistics that could be used to provide a representative measure of the biological quality of a river, this was especially unfortunate since these two taxa are the most commonly occurring taxa by far (they occur in about $95 \%$ of all samples). The difference between the lower-bound and truly representative scores was particular large in the case of Oligochaeta and Chironomidae. In this data-driven study the PO score of each taxon has moved from its BMWP (lower bound) score to a MNWH score that is, hopefully, rather closer to its truly representative score. In the case of Oligochaeta and Chironomidae the size of this move was so great that it has effectively taken three consecutive analyses to complete it $(\mathrm{WH}, \mathrm{NWH}$ and $\mathrm{MNWH}$ ). That is, their BMWP, $\mathrm{WH}, \mathrm{NWH}$ and MNWH PO scores progressed as follows: Oligochaeta $(1,3.5,3.5,4.5)$; Chironomidae $(2,3.7,3.6,4.6)$. Given their ubiquity the impact of using the new scores on ASPT values may be significant.

\subsection{Possible future developments}

Two possible solutions concerning the use of Oligochaeta and Chironomidae as indicators are as follows:

4.7.1 Abandon them as recommended by Pinder \& Farr (1987). This would have no impact on the $5 \%$ of sites where they are absent and little impact on those remaining, except for those where very few taxa are present. In the extreme case where they are the only taxa present the BMWP score for the site would be reduced from 3 to 0 . However, this may not prove problematic now that several extra families from the Order Diptera have been added to the list of indicator, some of which are quite pollution-tolerant.

4.7.2 Replace Oligochaeta by its families and Chironomidae by its tribes or selected species. The scores of these were derived where data was sufficient and will be reported in a separate paper. This would be the better solution, but would involve extra monitoring effort and training. 
Another possible development would be to use abundance-related scores for each of the three site types, as proposed by Walley and Hawkes (1997). Although the use of such site-abundance-related scores would add extra reliability to the final quality classification, it would require a little extra monitoring effort.

\section{CONCLUSIONS}

The revision of BMWP scores exercise described here tested four metrics and after evaluation adopted a version of that used by Walley and Hawkes $(1996,1997)$ incorporating modified scores for Oligochaeta and Chironomidae, known as MNWH. The approach has produced scores that are more representative of each taxon's sensitivity to pollution across its component species, whereas the BMWP allocated scores on the basis of the perceived sensitivity of the most pollution tolerant species within each taxon. Thus, the new MNWH scores can be considered to be better suited to the task of deriving classifications that are truly representative of river water quality.

Full details have been given of the MNWH scores, including 19 additional taxa, mainly Diptera, and a further 16 taxa that are the result of splitting eight BMWP composite taxa. In order to facilitate the analysis of historic data scores are given for the eight redundant BMWP composite taxa.

A new system based upon these scores will have an extended and refined taxonomic list, and the added benefit of AR scores. It has flexibility of application, since it can be used on PO data or abundance data, or a combination of the two. Its development should significantly enhance the precision and reliability of future river water quality classifications under the WFD.

\section{ACNOWLEDGEMENTS}

The work reported here formed part of SNIFFER (Scottish and Northern Ireland Forum for Environmental Research) Project WFD72A. Particular thanks are due to Dr. A. Veal (Project Manager) and Dr. J. Murray-Bligh from the EA and Dr R. Guthrie from SEPA. Thanks are also due to Dr. H.A. Hawkes for invaluable contributions made during the project. 


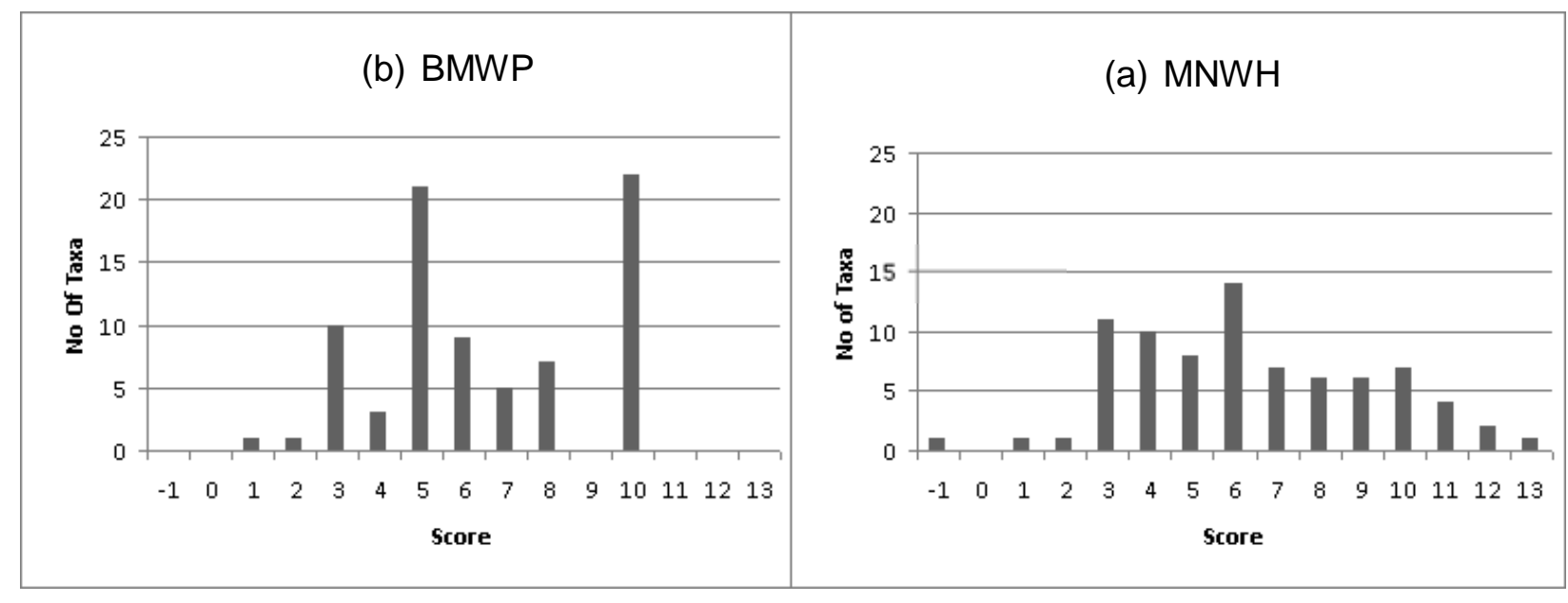

Figure 1. Histograms of number of taxa in each band of unit width: (a) original BMWP (Biological Montoring Working Party), (b) MNWH (Modified New WH).
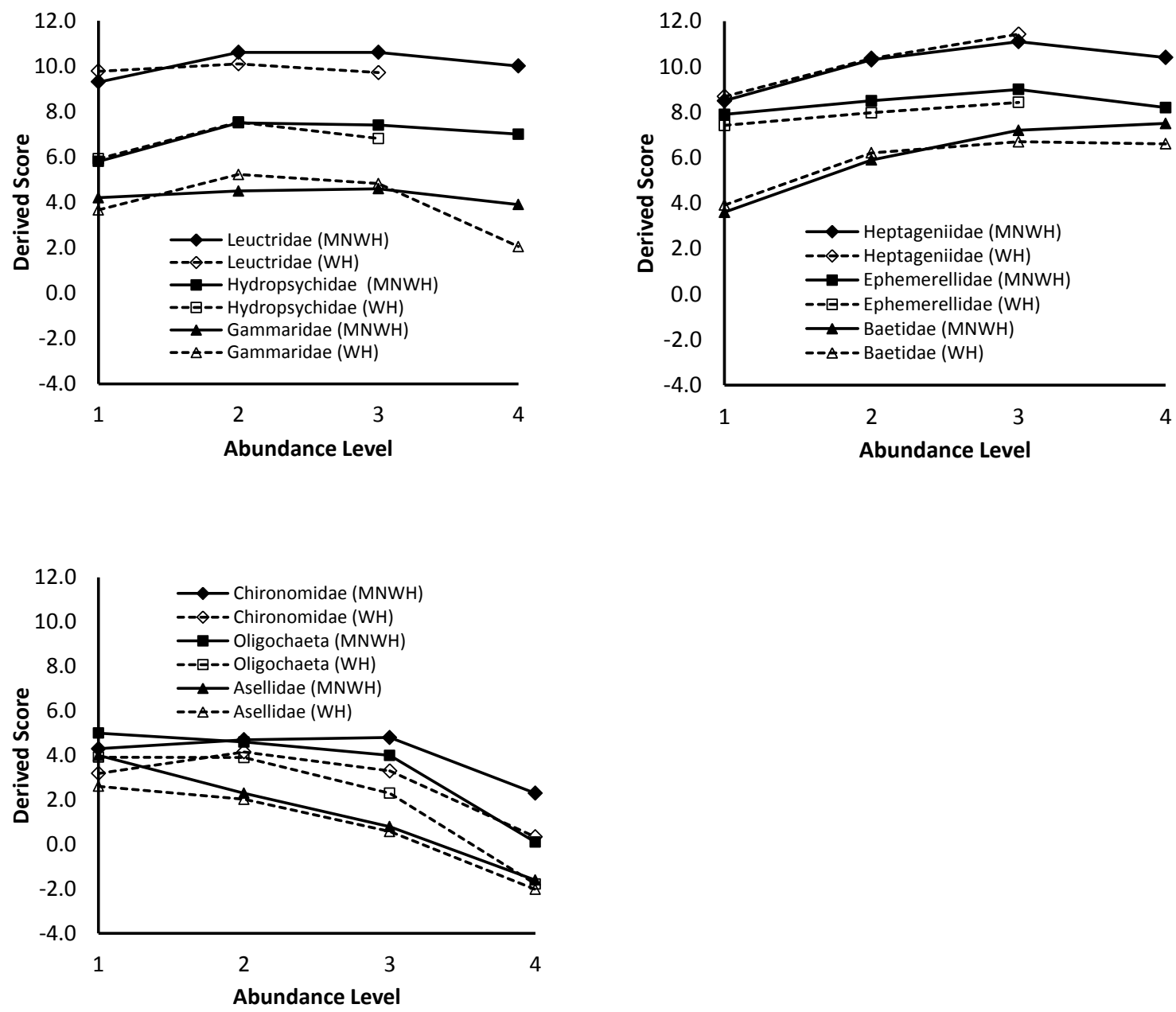

Figure 2. Comparison of MNWH (Modified New WH) and WH scores with abundance level for selected families 
Table 1. The 'Pre-BMWP' scores, BMWP scores, the presence only and abundance-related MNWH and WH scores.

\begin{tabular}{|c|c|c|c|c|c|c|c|c|c|c|c|c|c|c|c|c|c|}
\hline & \multirow{3}{*}{$\begin{array}{c}\text { Pre } \\
\text { BMWP }\end{array}$} & \multirow[b]{3}{*}{ BMWP } & \multicolumn{10}{|c|}{ MNWH Scores } & \multicolumn{5}{|c|}{ WH Scores } \\
\hline & & & \multicolumn{2}{|c|}{ Presence } & \multicolumn{2}{|c|}{ Abund. 1} & \multicolumn{2}{|c|}{ Abund. 2} & \multicolumn{2}{|c|}{ Abund 3.} & \multicolumn{2}{|c|}{ Abund. 4} & & Abunc & dance & Leve & \\
\hline & & & Scr & No & Scr & No & Scr & No & Scr & No & Scr & No & PO & 1 & 2 & 3 & 4 \\
\hline TRICLADA & & & & & & & & & & & & & & & & & \\
\hline Dendrocoelidae & 3 & 5 & 3.0 & 8087 & 3.0 & 7469 & 2.6 & 618 & & & & & 3.1 & 3.2 & 1.5 & & \\
\hline Dugesiidae & 4 & 5 & 2.9 & 5862 & 2.8 & 4692 & 3.1 & 1131 & 1.3 & 39 & & & & & & & \\
\hline Planariidae & 4 & 5 & 4.9 & 34500 & 4.7 & 23892 & 5.4 & 9681 & 5.4 & 857 & 5.1 & 70 & 4.2 & 4.3 & 4.0 & 4.1 & \\
\hline MOLLUSCA & & & & & & & & & & & & & & & & & \\
\hline Neritidae & 6 & 6 & 6.4 & 4793 & 6.4 & 2807 & 6.5 & 1840 & 6.9 & 146 & & & 7.5 & 7.8 & 7.4 & 2.5 & \\
\hline Viviparidae & 6 & 6 & 5.7 & 1598 & 5.2 & 1180 & 6.7 & 384 & 10.1 & 34 & & & 6.3 & 6.6 & 5.1 & & \\
\hline Unionidae & 6 & 6 & 5.3 & 3188 & 5.2 & 3053 & 6.8 & 135 & & & & & 5.2 & 5.1 & 5.8 & & \\
\hline Sphaeriidae & 3 & 3 & 3.9 & 66095 & 4.4 & 29791 & 3.5 & 30085 & 3.4 & 5786 & 2.3 & 433 & 3.6 & 3.7 & 3.7 & 2.9 & 0.3 \\
\hline Lymnaeidae & 3 & 3 & 3.3 & 44655 & 3.6 & 32091 & 2.5 & 11309 & 1.2 & 1184 & 0.2 & 71 & 3.0 & 3.5 & 2.3 & 0.8 & 0.1 \\
\hline Planorbidae & 3 & 3 & 3.1 & 32547 & 3.2 & 22148 & 3.0 & 9699 & 2.4 & 700 & & & 2.9 & 3.1 & 2.5 & 2.6 & 0.3 \\
\hline Valvatidae & 3 & 3 & 3.2 & 15896 & 3.3 & 10265 & 3.1 & 5084 & 2.7 & 547 & & & 2.8 & 3.0 & 2.5 & 2.5 & \\
\hline Physidae & 2 & 3 & 2.4 & 16894 & 2.7 & 12264 & 2.0 & 4250 & 0.4 & 380 & & & 1.8 & 1.8 & 2.0 & 1.8 & \\
\hline Acroloxidae & 6 & 6 & 3.6 & 3363 & 3.6 & 2998 & 3.8 & 365 & & & & & & & & & \\
\hline Ancylidae & 6 & 6 & 5.7 & 38455 & 5.8 & 24597 & 5.5 & 12913 & 5.5 & 904 & 4.4 & 41 & 5.6 & 5.8 & 5.2 & 3.6 & \\
\hline Bithyniidae & 3 & 3 & 3.7 & 10199 & 3.6 & 6475 & 3.8 & 3480 & 3.3 & 244 & & & & & & & \\
\hline Hydrobiidae & 3 & 3 & 4.2 & 54307 & 4.1 & 22818 & 4.2 & 23842 & 4.6 & 6426 & 3.7 & 1221 & 3.9 & 3.8 & 4.1 & 4.1 & 2.7 \\
\hline Dreissenidae & & & 3.7 & 206 & 3.7 & 206 & & & & & & & & & & & \\
\hline OLIGOCHAETA & & & & & & & & & & & & & & & & & \\
\hline Oligochaeta & & 1 & 4.5 & 84841 & 5.0 & 18387 & 4.6 & 47732 & 4.0 & 16826 & 0.1 & 1896 & 3.5 & 3.9 & 3.9 & 2.3 & -1.8 \\
\hline HIRUDINIA & & & & & & & & & & & & & & & & & \\
\hline Piscicolidae & 4 & 4 & 5.2 & 10092 & 5.2 & 9822 & 4.9 & 270 & & & & & 5.0 & 5.0 & 4.6 & & \\
\hline Glossiphoniidae & 3 & 3 & 3.2 & 52834 & 3.4 & 41402 & 2.5 & 11158 & 0.8 & 274 & & & 3.1 & 3.2 & 2.6 & 1.5 & \\
\hline Erpobdellidae & 3 & 3 & 3.1 & 52255 & 3.6 & 38037 & 2.0 & 13620 & -0.8 & 572 & 3.7 & 26 & 2.8 & 3.0 & 2.1 & -0.8 & \\
\hline Hirudinidae & 3 & 3 & -0.8 & 251 & -0.8 & 251 & & & & & & & 0.0 & -2.1 & & & \\
\hline CRUSTACEA & & & & & & & & & & & & & & & & & \\
\hline Astacidae & 8 & 8 & 7.9 & 1158 & 7.9 & 1103 & 8.9 & 55 & & & & & 9.0 & 9.0 & & & \\
\hline Corophiidae & 6 & 6 & 5.8 & 748 & 5.7 & 467 & 5.8 & 252 & 5.9 & 29 & & & 6.1 & 6.0 & 6.5 & 4.2 & 7.6 \\
\hline Asellidae & 2 & 3 & 2.8 & 55353 & 4.0 & 23441 & 2.3 & 25899 & 0.8 & 5347 & -1.6 & 666 & 2.1 & 2.6 & 2.0 & 0.6 & -2.0 \\
\hline Crangonyctidae & 4 & 6 & 3.9 & 6901 & 3.8 & 3993 & 4.0 & 2633 & 3.6 & 275 & & & & & & & \\
\hline Gammaridae & 4 & 6 & 4.4 & 65721 & 4.2 & 18946 & 4.5 & 31874 & 4.6 & 12701 & 3.9 & 2200 & 4.5 & 3.7 & 5.2 & 4.8 & 2.0 \\
\hline Niphargidae & 4 & 6 & 6.3 & 286 & 6.3 & 286 & & & & & & & & & & & \\
\hline EPHEMEROPTERA & & & & & & & & & & & & & & & & & \\
\hline Siphlonuridae (incl & & & & & & & & & & & & & & & & & \\
\hline Ameletidae) & 10 & 10 & 11.5 & 183 & 11.3 & 146 & 12.2 & 37 & & & & & 11.0 & 11.0 & & & \\
\hline Heptageniidae & 10 & 10 & 9.7 & 28165 & 8.5 & 10957 & 10.3 & 13974 & 11.1 & 3170 & 10.4 & 64 & 9.8 & 8.7 & 10.4 & 11.4 & \\
\hline Ephemeridae & 10 & 10 & 8.4 & 16240 & 8.3 & 11739 & 8.8 & 4261 & 9.4 & 240 & & & 9.3 & 8.9 & 10.5 & 10.3 & \\
\hline Leptophlebiidae & 10 & 10 & 8.8 & 15980 & 8.8 & 12002 & 9.1 & 3654 & 9.2 & 324 & & & 8.9 & 8.7 & 9.5 & 9.2 & \\
\hline Ephemerellidae & $10 \& 8$ & 10 & 8.2 & 22375 & 7.9 & 11602 & 8.5 & 7748 & 9.0 & 2826 & 8.2 & 199 & 7.7 & 7.4 & 8.0 & 8.4 & 5.7 \\
\hline Potamanthidae & 10 & 10 & 10.0 & 80 & 9.8 & 52 & 10.4 & 28 & & & & & 7.6 & 7.6 & & & \\
\hline Caenidae & 7 & 7 & 6.5 & 29352 & 6.6 & 15147 & 6.4 & 11584 & 6.6 & 2505 & 6.2 & 116 & 7.1 & 6.7 & 7.7 & 7.7 & 9.6 \\
\hline Baetidae & $9 \& 4$ & 4 & 5.5 & 70229 & 3.6 & 21542 & 5.9 & 34909 & 7.2 & 13151 & 7.5 & 627 & 5.3 & 3.9 & 6.2 & 6.7 & 6.6 \\
\hline PLECOPTERA & & & & & & & & & & & & & & & & & \\
\hline Perlidae & 10 & 10 & 12.7 & 2686 & 12.6 & 2198 & 13.0 & 488 & & & & & 12.5 & 12.6 & 12.1 & & \\
\hline Chloroperlidae & 10 & 10 & 11.6 & 11026 & 11.4 & 7670 & 12.2 & 3254 & 11.9 & 102 & & & 12.4 & 12.1 & 13.2 & 13.1 & \\
\hline Taeniopterygidae & 10 & 10 & 11.3 & 6783 & 11.0 & 4582 & 11.9 & 2037 & 12.1 & 164 & & & 10.8 & $\mid 10.5$ & 11.3 & 10.7 & \\
\hline Perlodidae & 10 & 10 & 10.8 & 17369 & 10.5 & 12161 & 11.5 & 5033 & 10.7 & 175 & & & 10.7 & 10.4 & 11.5 & 8.7 & \\
\hline Capniidae & 10 & 10 & 9.6 & 528 & 9.7 & 444 & 9.4 & 84 & & & & & 10.1 & 10.1 & & & \\
\hline Leuctridae & 10 & 10 & 10.0 & 26081 & 9.3 & 12192 & 10.6 & 11775 & 10.6 & 2038 & 10.0 & 76 & 9.9 & 9.8 & 10.1 & 9.7 & \\
\hline Nemouridae & $9 \& 7$ & 7 & 9.3 & 20525 & 8.7 & 14360 & 10.7 & 5562 & 10.7 & 603 & & & 9.1 & 8.4 & 10.3 & 10.7 & \\
\hline ZYGOPTERA & & & & & & & & & & & & & & & & & \\
\hline Calopterygidae & ? & 8 & 6.0 & 11613 & 5.9 & 10150 & 6.2 & 1463 & & & & & 6.4 & 6.3 & 7.2 & & \\
\hline Platycnemididae & 6 & 6 & 6.0 & 1005 & 5.9 & 956 & 6.9 & 49 & & & & & 5.1 & 5.1 & & & \\
\hline Coenagriidae & 2 & 6 & 3.5 & 10320 & 3.4 & 8569 & 3.8 & 1751 & & & & & 3.5 & 3.3 & 4.4 & 4.0 & \\
\hline ANISOPTERA & & & & & & & & & & & & & & & & & \\
\hline Cordulegasteridae & 8 & 8 & 9.8 & 1572 & 9.8 & 1519 & 9.6 & 53 & & & & & 8.6 & 8.7 & 5.7 & & \\
\hline Aeshnidae & 8 & 8 & 4.7 & 654 & 4.7 & 654 & & & & & & & 6.2 & 6.2 & & & \\
\hline Libellulidae & 8 & 8 & 4.1 & 466 & 4.1 & 466 & & & & & & & 5.0 & 5.0 & & & \\
\hline
\end{tabular}




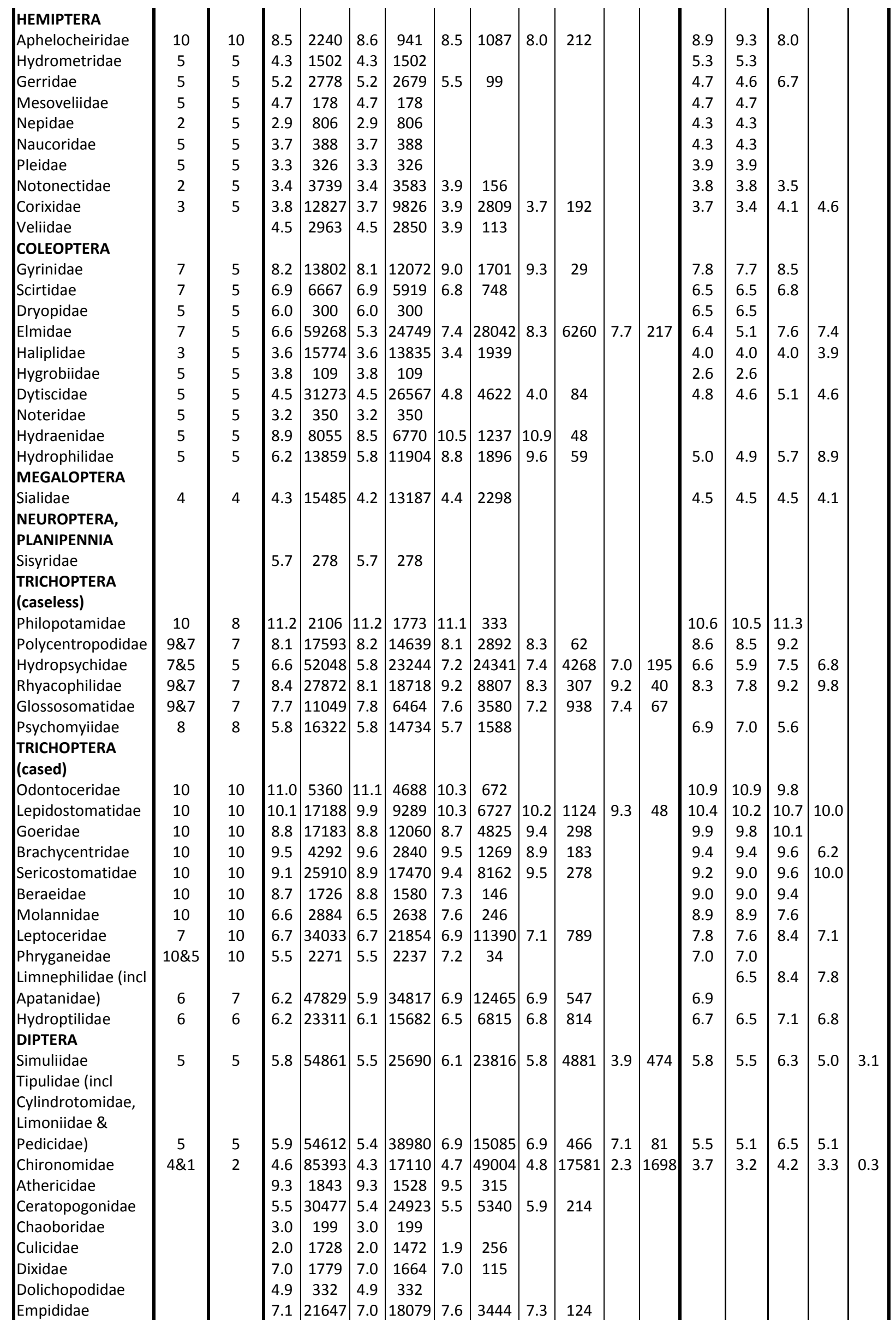




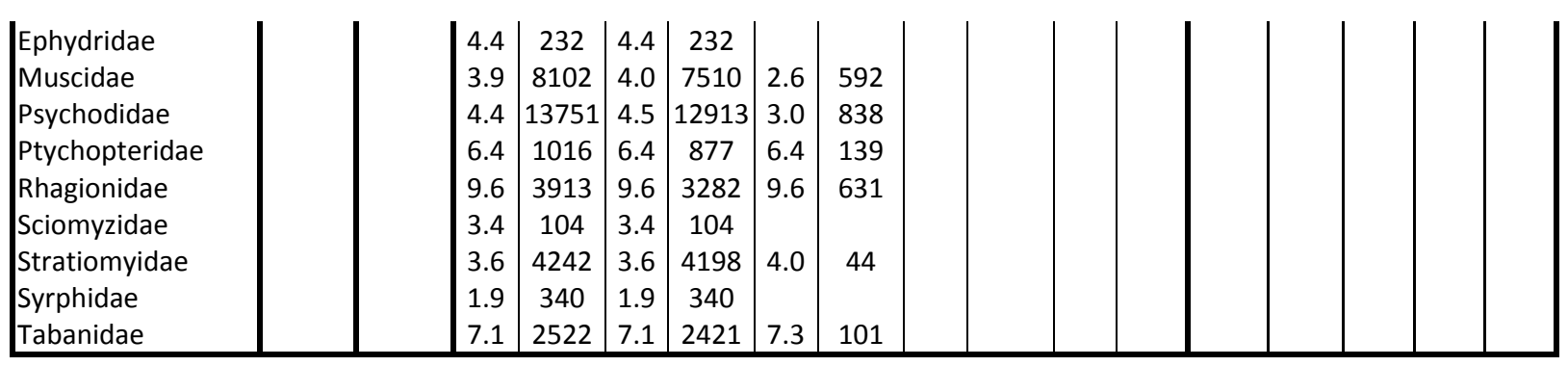

Table 2. Results of regression analysis when revised PO scores using metrics EQI ${ }_{\text {MASPT }}$ and MNWH are compared with the BMWP and 'Pre-BMWP' scores.

\begin{tabular}{|c|c|c|c|c|c|}
\hline Ind Var $(\mathrm{x})$ & Dep Var $(\mathrm{y})$ & Slope & $\mathrm{R}$ & St Err Est & $\mathrm{p}$-value \\
\hline BMWP & EQI $_{\text {MASPT }}$ & 1.0467 & 0.8007 & 1.8978 & $<0.001$ \\
BMWP & MNWH & 0.9557 & 0.8040 & 1.6434 & $<0.001$ \\
\hline Pre-BMWP & EQI & 1.0610 & 0.8083 & 1.8649 & $<0.001$ \\
Pre-BMWP & MNWH & 0.9780 & 0.8806 & 1.3097 & $<0.001$ \\
\hline
\end{tabular}

Table 3. MNWH scores for the removed BMWP composite taxa. (Note: these values are provided to allow the evaluation of historical data in which individual families have not been recorded).

\begin{tabular}{|c|c|c|c|c|c|c|c|c|c|c|c|c|}
\hline & & & \multicolumn{10}{|c|}{ MNWH Scores } \\
\hline & \multirow{2}{*}{ Pre BMWP } & \multirow[b]{2}{*}{ BMWP } & \multicolumn{2}{|c|}{ Presence } & \multicolumn{2}{|c|}{ Abund. 1} & \multicolumn{2}{|c|}{ Abund. 2} & \multicolumn{2}{|c|}{ Abund 3.} & \multicolumn{2}{|c|}{ Abund. 4} \\
\hline & & & Scr & No & Scr & No & Scr & No & Scr & No & Scr & No \\
\hline TRICLADA & & & & & & & & & & & & \\
\hline Planariidae (incl. Dugesiidae) & 4 & 5 & 5.0 & 39798 & 4.8 & 27279 & 5.4 & 11447 & 5.3 & 995 & 4.8 & 77 \\
\hline MOLLUSCA & & & & & & & & & & & & \\
\hline Ancylidae (incl. Acroloxidae) & 6 & 6 & 5.8 & 43887 & 5.9 & 28682 & 5.6 & 14212 & 5.4 & 950 & 4.6 & 43 \\
\hline Hydrobiidae (incl. Bithyniidae) & 3 & 3 & 4.2 & 60073 & 4.1 & 25277 & 4.2 & 26668 & 4.5 & 6889 & 3.7 & 1239 \\
\hline CRUSTACEA & & & & & & & & & & & & \\
\hline Gammaridae (incl. Crangonyctidae \& Niphargidae) & 4 & 6 & 4.5 & 71875 & 4.3 & 20506 & 4.7 & 35562 & 4.7 & 13536 & 3.9 & 2271 \\
\hline COLEOPTERA & & & & & & & & & & & & \\
\hline Hydrophilidae (incl. Hydraenidae) & 5 & 5 & 7.4 & 23186 & 7.0 & 19728 & 9.5 & 3348 & 10.2 & 110 & & \\
\hline Dytiscidae (incl. Noteridae) & 5 & 5 & 4.7 & 33155 & 4.7 & 28105 & 5.0 & 4935 & 4.2 & 115 & & \\
\hline TRICHOPTERA & & & & & & & & & & & & \\
\hline Rhyacophilidae (incl. Glossosomatidae) & $9 \& 7$ & 7 & 8.2 & 36033 & 7.9 & 21465 & 8.8 & 13116 & 7.5 & 1343 & 8.1 & 109 \\
\hline Psychomyiidae (incl. Ecnomidae) & 8 & 8 & 5.9 & 16891 & 5.9 & 15265 & 5.8 & 1626 & & & & \\
\hline
\end{tabular}


Table 4. Average BMWP (Biological Monitoring Working Party) and MNWH (Modified New WH) present-only scores for each of the main taxonomic groups of BMWP

\begin{tabular}{|l|c|c|c|c|c|}
\hline $\begin{array}{l}\text { Taxonomic Group (No. of } \\
\text { BMWP taxa in group) }\end{array}$ & $\begin{array}{l}\text { Avg. BMWP } \\
\text { score }\end{array}$ & $\begin{array}{l}\text { Avg MNWH Scr } \\
\text { (BMWP Taxa) }\end{array}$ & $\begin{array}{l}\text { Increase in } \\
\text { Avg. Score }\end{array}$ & \multicolumn{2}{|c|}{ WH Scores } \\
AvgScore & Increase \\
\hline OLIGOCHAETA (1) & 1.0 & 4.5 & 3.5 & 3.5 & 2.5 \\
PLECOPTERA (7) & 9.6 & 10.8 & 1.2 & 10.8 & 1.2 \\
TRICHOPTERA (caseless) (6) & 7.0 & 8.0 & 1.0 & 8.2 & 1.2 \\
COLEOPTERA (10) & 5.0 & 5.9 & 0.9 & 5.5 & 0.5 \\
DIPTERA (3) & 4.0 & 5.4 & 1.4 & 5.0 & 1.0 \\
MEGALOPTERA (1) & 4.0 & 4.3 & 0.3 & 4.5 & 0.5 \\
CRUSTACEA (6) & 5.0 & 5.3 & 0.3 & 4.7 & -0.3 \\
MOLLUSCA (12) & 4.2 & 4.3 & 0.1 & 4.3 & 0.1 \\
EPHEMEROPTERA (8) & 8.9 & 8.6 & -0.3 & 8.4 & -0.5 \\
HIRUDINIA (4) & 3.3 & 2.7 & -0.6 & 2.8 & -0.5 \\
TRICLADA (3) & 5.0 & 4.0 & -1.0 & 3.6 & -1.4 \\
HEMIPTERA (10) & 5.6 & 4.4 & -1.1 & 4.9 & -0.7 \\
TRICHOPTERA (cased) (11) & 9.4 & 8.0 & -1.3 & 8.7 & -0.7 \\
ZYGOPTERA (3) & 6.7 & 5.2 & -1.5 & 5.0 & -1.7 \\
ANISOPTERA (3) & 8.0 & 6.2 & -1.8 & 6.6 & -1.4 \\
\hline
\end{tabular}




\section{REFERENCES}

Biological Monitoring Working Party (1978) Final Report: Assessment and Presentation of the Biological Quality of Rivers in Great Britain. Unpublished Report. Dept. of Envir., Water Datga Unit.

Chesters R.K. (1980) Biological Monitoring Working Party: The 1978 National Testing Exercise. Tech Mem. No. 19, Dept of Envir., Water Data Unit.

Capítulo A.R., Tangorra M. and Ocón C. (2001) Use of macroinvertebrates to assess the biological status of Pampean streams in Argentina. Aquatic Ecology, 35, 109-119.

Chadd R. and Extance C.A. (2004) The conservation of freshwater macroinvertebrates populations: a community based classification scheme. Aquatic Conservation: Marine and Freshwater Ecosystems 14, 597-624.

Clarke R.T., Davy-Bowker J., Dunbar M., Laize C., Scarlett P. and Murphy J. (2011) Enhancement of the River Invertebrate Classification Tool. Final Report SNIFFER Project WFD119. Edinburgh, SNIFFER.

Davies P.E. (2000) Development of a national river bioassessment system (AUSRIVAS) in Australia. In: Wright, J.F., D.W. Sutcliffe \& M.T. Furse (Eds). Assessing the biological quality of fresh waters: RIVPACS and other techniques. Ambleside, Freshwater Biological Association, 113-124.

Davy-Bowker J., Murphy J.F., Rutt G.P., Steel J.E.C. and Furse M.T. (2005) The development and testing of a macroinvertebrate biotic index for detecting the impact of acidity on streams. Archiv fur Hydrobiologie 163, 383-403.

Davy-Bowker J., Clark R., Corbin T., Vincent H., Pretty J., Hawczak A., Blackburn J., Murphy J. and Jones I. (2008). River Invertebrate Classification Tool. Final Report SNIFFER Project WFD72C. Edinburgh, SNIFFER.

European Parliament and Council of the European Union. 2000. Directive 2000/60/EC of the European Parliament and of the Council of 23 October 2000 establishing a framework for Community action in the field of water policy. Official Journal of the European Communities, L 327: 1-72.

Extence C.A., Balbi D.M., and Chadd R.P. (1999) River flow indexing using British benthic macroinvertebrates: A framework for setting hydroecolgical objectives. Regulated Rvers: Research and Management 15, 543-574.

Extence C.A., Chadd R.P., England J., Dunbar M.J., Wood P.J., and Taylor E.D. (2011) The assessment of fine sediment accumulation in rivers using macro-invertebrate community response. River Research and Applications (published online Sept 2011).

Hargett E.G., Zumberge J.R., Hawkins C.P. and Olson J.R. (2007) Development of a RIVPACS-type predictive model for bioassessment of wadable streams in Wyoming. Ecological Indicators 7, 807-826.

Hassal C., Thompson D.J. and Harvey I.F. (2010) The impact of climate-induced distributional changes on the validity of biological water quality metrics. Environmental Monitoring and Assessment 160, 451456.

Hawkes, H.A. (1997). Origin and development of the Biological Monitoring Working Party score system. Water Research, Vol. 32, No. 3, pps $964-968$.

Hawkes, H.A. (2007). Unpublished communication.

Hawkins C.P., Norris R.H., Hogue J.N. and Feminella J.W. (2000) Development and evaluation of predictive models for measuring the biological integrity of streams. Ecological Applications 10, 14561477.

Hawkins C.P. (2006) Quantifying biological integriaty by taxonomic completeness: evaluation of a potential indicator for use in regional and global-scale assessments. Ecological Applications 16, 12771294. 
Hemsley-Flint, B. (2000) Classification of the biological quality of rivers in England and Wales. In: Wright, J.F., D.W. Sutcliffe \& M.T. Furse (Eds). Assessing the biological quality of fresh waters: RIVPACS and other techniques. Ambleside, Freshwater Biological Association, 55-69.

Kownacki, A., Soszka, H., Kudelska, D. and Fleituch, T. (2004) Bioassessment of Polish rivers based on macroinvertebrates. In: Geller W. [Ed.] Proceedings of the 11th Magdeburg Seminar on Waters in Central and Eastern Europe: Assessment. Protection. Management. UFZ-Bericht Nr. 18/2004, Leipzig: 250-251.

Kokeš, J., Zahrádková, S., Němejcová, D, JHodovský, J and Soldán, T. (2006) The PERLA system in the Czech Republic: a multivariate approach for assessing the ecological status of running waters. Hydrobiologia 566: 343-354.

Lorenz A., Hering D., Feld C.K. and Rolaufs P. (2004) A new method for assessing the impact of hydromorphological degradation on the macroinvertebrate fauna of five German stream types. Hydrobiologia 516, 107-127.

Moss D., Furse M.T, Wright J.F, and Armitage P.D. (1987). The prediction of the macro-invertebrate fauna of unpolluted running-water sites in Great Britain using environmental data. Freshwater Biology 17, 41-52.

Mustow, S.E. (2002) Biological monitoring in rivers of Thailand: Use and adaptation of the BMWP score. Hydrobiologia, 479, 191-229.

Moss D., Furse M.T, Wright J.F, and Armitage P.D. (1987) The prediction of the macro-invertebrate fauna of unpolluted running-water sites in Great Britain using environmental data. Freshwater Biology 17, 41-52.

Murphy J., Davy-Bowker J., McFarland B. and Ormerod S.J. (in review) A diagnostic biotic index for assessing acidity in sensitive streams in Britain. In review: Ecological Indicators.

Murray-Bligh, J.A.D., M.T. Furse, F.H. Jones, R.J.M. Gunn, R.A. Dines \& J.F. Wright (1997) Procedure for collecting and analysing macro-invertebrate samples for RIVPACS. Wareham: Institute of Freshwater Ecology and The Environment Agency.

Paisley, M.F., Walley, W.J. \& Trigg D.J. (2007). Revision and Testing of BMWP Scores. Final Report for Scottish and Northern Ireland Forum for Environmental Research (SNIFFER) Project WFD72A. Edinburgh, SNIFFER. Available from http://www.sniffer.org.uk.

Pinder L.C.V. \& Farr I.S. (1987). Biological survelillance of water quality - 3. The influence of organic enrichment on the macroinvertebrate fauna of small chalk streams. Archiv fur Hydrobiologie 109; 619-37.

Smith, M.J., Kay, W.R., Edward, D.H.D., Papas, P.J., Richardsons, K.StJ., Simpson, J.C, Pinder, A.N, Cale, D.J., Horwitz, P.H.J., Davis, J.A., Yung, F.H., Norris, R.H. and Halse, S.A. (1999) AusRivAS: using macroinvertebrates to assess ecological condition of rivers in Western Australia. Freshwater Biology, Vol 41, pp 269-282.

Walley, W.J. \& Hawkes H.A. (1996). A computer-based reappraisal of the Biological Monitoring Working Party scores using data from the 1990 river quality survey of England and Wales. Water Research, Vol. 30, No. 9, pp $2086-2094$.

Walley, W.J. \& Hawkes H.A. (1997). A computer-based development of the Biological Monitoring Working Party score system incorporating abundance rating, site type and indicator value. Water Research, Vol. 31, No. 2, pp $201-210$.

Walley, W.J., Grbovic J. \& Dzeroski S. (2001). A reappraisal of saprobic values and indicator weights based on Slovenian river quality data. Water Research, Vol. 35, No. 18, pp 4285-4292.

Wright, J.F., Furse, M.T. \& Armitage, P.D. (1993) RIVPACS - a technqiue for evaluating the biological quality of rivers in the U.K. European Water Pollution Control 3, 15-25. 
Wright J F, Sutcliffe D W and Furse M T (Eds.) (2000) Assessing the biological quality of fresh waters: RIVPACS and other techniques. Freshwater Biological Association, Ambleside, UK, 400pp.

Zamora-Munoz C. and Alba-Tercedor J. (1996) Bioassessment of organically-polluted Spanish rivers, using a biotic index and multivariate methods. Journal of the North American Benthological Society, 15, 332-352. 